\title{
HLA haplotypes in non-familial rheumatoid arthritis
}

\author{
L LEGRAND, ${ }^{1}$ G M LATHROP ${ }^{2}$ T BARDIN $^{3}$ A MARCELLI-BARGE ${ }^{1}$ \\ A DRYLL, ${ }^{3}$ DEBEYRE, ${ }^{3}$ AND A RYCKEWAERT ${ }^{3}$
}

From the ${ }^{1}$ INSERM U 93, Hôpital St Louis, 2 place du Dr Fournier, 75475, Paris, France; the ${ }^{2}$ Centre d'Etude Polymorphisme Humain, Collège de France, 3 rue d'Ulm, 75005, Paris, France; and the ${ }^{3}$ Clinique de Rhumatologie, Hôpital Lariboisière, 6 rue Guy Patin, 75010, Paris, France

SUmmary The frequencies of HLA-A, B, C, DR, and BF haplotypes in 44 unrelated Caucasian patients with definite seropositive rheumatoid arthritis (RA) were compared with haplotype frequencies in controls. Overall, the patients had an increased risk for HLA-DR4, DR3, and DR2 antigens, but frequencies of certain DR4 or DR3 haplotypes were not increased, suggesting the importance of other HLA loci for the evaluation of risk. The presence of DR4 alone was not found to produce an increased risk for RA since the frequencies of certain DR4 haplotypes were similar in patients and controls. Increased frequencies of HLA-B18,DR4, HLA-B15,DR4, and HLA-A1,B8,Cw7,DR3 haplotypes were found in patients. RA susceptibility has been found to be associated with the last two haplotypes in some studies of multiple case families, suggesting that similar genetic mechanisms may underlie the disease in familial and sporadic forms.

Genetic factors have an important role in the pathogenesis of seropositive rheumatoid arthritis (RA) as shown by the strong association with HLA-DR4 $4^{1-4}$ and non-random sharing of haplotypes in affected relatives in multiple case families. ${ }^{5}$ The mechanism of genetic predisposition to RA, however, is still poorly understood.

Previously, we have reported positive associations between RA and HLA-DR1, DR2, and DR3 antigens (with smaller relative risks than HLADR4), ${ }^{7}$ and several studies have shown increased risks associated with other loci of the HLA region, alone or in combination with HLA-DR4. ${ }^{2} 8-11$ An investigation of haplotype frequencies in multiple case families suggested that relative risks vary for different haplotypes carrying the same HLA-DR antigen, ${ }^{11}$ but no studies of haplotype distributions in non-familial RA have been reported. To gain further insight into the association between HLA loci and RA we have undertaken a study of the distribution of HLA haplotypes in 44 unrelated seropositive patients with RA and 184 controls.

\section{Patients and methods}

Forty four unrelated patients with definite rheuma-

Accepted for publication 24 November 1986.

Correspondence to Dr G M Lathrop, Hughes Medical Institute, University of Utah, Salt Lake City, Utah 84132, USA. toid arthritis according to the criteria of the American Rheumatism Association ${ }^{12}$ were studied. All patients were Caucasians living in the region of Paris. All had positive titres for rheumatoid factor by the Waaler-Rose $(\geqslant 1 / 32)$ and latex $(\geqslant 1 / 80)$ tests. Sjögren's syndrome, defined as the conjunction of an abnormal Schirmer's test and keratoconjunctivitis demonstrated by rose bengal staining, was found in 16 of the 42 patients who underwent these tests. HLA-A, B, and C antigens were identified with the conventional microcytotoxicity test. Enriched suspensions of $\mathrm{B}$ cells were prepared as described by Pellegrino et al for HLA-DR determinations. ${ }^{13} \mathrm{BF}$ typing was obtained by electrophoresis followed by immunodiffusion. ${ }^{14}$ Family studies allowed haplotype determinations for all patients. The control series consisted of 184 unrelated healthy Caucasians living in the Paris area. Family studies also allowed determinations of haplotypes in controls.

The total heterogeneity $\chi^{2}$ statistic $^{15}$ was used to assess HLA-DR antigen and haplotype frequencies in patients and controls. The number of comparisons made is reflected in the degrees of liberty assigned to the $\chi^{2}$ statistic, and therefore the significance levels are not adjusted for the number of antigens at each locus. ${ }^{16}$ The results were confirmed using a $\chi^{2}$ test with Yates's correction. ${ }^{17}$ Two-locus haplotype analysis was performed for HLA-DR antigens that were significantly associated 
with RA, and alleles at the HLA-A, B, C, or BF loci when they were present for 15 or more haplotypes. Haplotype association was deemed to be present when third order terms were significant in the log-linear model. ${ }^{15}$ Association with specific haplotype combinations was evaluated using deviations from expected and observed values ${ }^{15}$ and confirmed with Fisher's exact test or a $\chi^{2}$ test with Yates's correction.

\section{Results}

Table 1 shows the HLA-DR frequencies in patients with RA and in controls. The distributions differed significantly in the two groups $\left(\chi_{9}^{2}=45.97, p<0 \cdot 001\right)$. The control group had gene frequencies similar to those reported for other European populations. ${ }^{18}$ The strong association between RA and HLA-DR4 may mask associations with other antigens, ${ }^{7}$ and thus the distributions were also compared when HLA-DR4 had been removed. The test for heterogeneity was again significant $\left(\chi_{8}^{2}=22 \cdot 31, \mathrm{p}<0.005\right)$. In addition to HLA-DR4, both HLA-DR3 and HLA-DR2 were significantly increased in patients. Risks for these antigens relative to others were 6.81 $(p<0.0001), 3.95(p<0.001)$, and $2.84(p<0.005)$ respectively. There was no heterogeneity of risk for the other HLA-DR antigens once the associations with HLA-DR4, DR3, and DR2 had been taken into account $\left(\chi_{7}^{2}=2.42, p=0.92\right)$.

The frequencies of two locus haplotypes were assessed by direct counting for HLA-A,DR, HLAB,DR, HLA-C,DR, and BF,HLA-DR. Risks for haplotypes carrying the same HLA-DR antigen were heterogeneous for HLA-A,DR $\left(\chi_{26}^{2}=40 \cdot 20\right.$, $\mathrm{p}<0 \cdot 05)$, HLA-B,DR $\left(\chi_{26}^{2}=50 \cdot 78, \mathrm{p}<0.01\right)$, and HLA-C,DR $\left(\chi_{16}^{2}=25 \cdot 64, p<0 \cdot 01\right)$, suggesting that other HLA loci are important in assessing the risk

Table 1 Distribution of HLA-DR alleles in rheumatoid arthritis patients ( 88 haplotypes) and controls (368 haplotypes)

\begin{tabular}{|c|c|c|}
\hline & $\begin{array}{l}\text { Patients with } \\
R A(n=44) \\
\text { No }(\%)\end{array}$ & $\begin{array}{l}\text { Controls } \\
(n=184) \\
\text { No }(\%)\end{array}$ \\
\hline DR1 & $4 \quad(4 \cdot 2)$ & $29 \quad(7 \cdot 9)$ \\
\hline DR2 & $19(19.8)$ & $57(15.5)$ \\
\hline DR3 & $20(20 \cdot 8)$ & $43(11 \cdot 7)$ \\
\hline DR4 & $30(31 \cdot 3)$ & $37(10 \cdot 1)$ \\
\hline DR5 & $8 \quad(8 \cdot 3)$ & $63(17 \cdot 2)$ \\
\hline DRw6 & $2(2 \cdot 1)$ & $24 \quad(6 \cdot 5)$ \\
\hline DR7 & $5 \quad(5 \cdot 2)$ & $52(14 \cdot 2)$ \\
\hline DRw8 & $\begin{array}{ll}0 & (0.0)\end{array}$ & $6(1 \cdot 6)$ \\
\hline DRw9 & $(0 \cdot 0)$ & $1 \quad(0 \cdot 3)$ \\
\hline 'Blank' & $(8 \cdot 3)$ & $55(15.0)$ \\
\hline
\end{tabular}

Table 2 Distribution of HLA haplotypes in patients (88 haplotypes) and controls (368 haplotypes) typed fơ $H L A-A, B, C$, and $D R$

\begin{tabular}{|c|c|c|c|}
\hline$H L A$ & $\begin{array}{l}\text { Patients with } \\
R A^{*}(n=44) \\
\text { No }(\%)\end{array}$ & $\begin{array}{l}\text { Controls* } \\
(n=184) \\
\text { No }(\%)\end{array}$ & $\begin{array}{l}\text { Significance } \\
\text { (p value }) \text { }\end{array}$ \\
\hline B18,DR4 & $4 \quad(4 \cdot 5)$ & $0(0 \cdot 0)$ & $\mathrm{p}<10^{-5}$ \\
\hline B15,DR4 & $5 \quad(5 \cdot 7)$ & $1(0 \cdot 3)$ & $\mathrm{p}<10^{-5}$ \\
\hline B27,DR4 & $0 \quad(0 \cdot 0)$ & $6(1 \cdot 7)$ & NS \\
\hline Cw2,DR4 & $\begin{array}{ll}0 & (0.0)\end{array}$ & $6(1 \cdot 7)$ & NS \\
\hline Other DR4 & $21(23.9)$ & $24(6.4)$ & $\mathrm{p}<10^{-6}$ \\
\hline $\mathrm{A} 1, \mathrm{~B} 8, \mathrm{Cw} 7, \mathrm{DR} 3$ & $13(14.8)$ & $6(1 \cdot 7)$ & $p<10^{-6}$ \\
\hline Other DR3 & $7 \quad(8 \cdot 0)$ & $37(10 \cdot 2)$ & NS \\
\hline DR2 & $19(21 \cdot 6)$ & $57(15 \cdot 7)$ & $p<0.01$ \\
\hline Other DR & $19(21 \cdot 6)$ & $227(62 \cdot 7)$ & \\
\hline
\end{tabular}

${ }^{*}$ Compared with haplotypes not carrying HLA-DR4, DR3, or DRA (other DR in table).

associated with a given HLA-DR antigen. № significant heterogeneity was found for $\mathrm{BF}, \mathrm{HL}$ DR haplotypes $\left(\chi_{7}^{2}=7 \cdot 45,0.5<p<0 \cdot 7\right)$.

Only one DR3 haplotype, HLA-A1,B8,Cw7,DR $\overrightarrow{30}$ was significantly increased in patients. This haplotypel had a risk of $17.2\left(\mathrm{p}<10^{-6}\right)$ relative to haplotypes not carrying DR4, DR3, or DR2, whereas the relative risk for other HLA-DR3 haplotypes was $1 \frac{7}{7}$ $(p=0 \cdot 45)$. The HLA-A1,B8,Cw7,DR3 haplotype was not associated with an increased frequency of Sjögren's syndrome, occurring six times in $16 \mathrm{RA}$ patients with this complication, and eight times the remaining 27 patients that were examineg $(\mathrm{p}=0.42)$.

We found that haplotypes carrying HLA-DRA and B27 or Cw2 had no increased risk of disease when compared with haplotypes not carrying HLA DR4, DR3, or DR2 ( $=0.60$ in both cases). 南 contrast, haplotypes carrying HLA-B18,DR4 HLA-B15,DR4 may have a higher risk than other HLA-DR4 haplotypes (including frequent haplotypes such as HLA-B40,DR4 and HLA-B44,DR\$ even when HLA-B27,DR4 and HLA-Cw2,DR4 are excluded from the comparisons $(p=0.06$ and $p=0$, respectively in a one sided test).

A summary of these haplotype associations given in Table 2 .

\section{Discussion}

These results show that haplotype combinations involving several loci of the HLA region have -7 substantial influence on risk in non-familial RS. From our data it appears that the presence of HL DR4 alone does not produce an increased risk of disease as the frequency of haplotypes bearifg HLA-DR4 and B27 or Cw2 is not increased. On the 
other hand, HLA-B18,DR4 and HLA-B15,DR4 may have greater risks for RA than other HLADR4 haplotypes, including common haplotypes such as HLA-B40,DR4 and HLA-B44,DR4. Interestingly, cosegregation of HLA-B15,DR4 with RA susceptibility has also been reported in patients with RA from multiple case families. ${ }^{11}$

The frequency of the haplotype HLA$\mathrm{A} 1, \mathrm{~B} 8, \mathrm{Cw} 7, \mathrm{DR} 3$ is increased in the patients studied here, with a relative risk that is statistically indistinguishable from that for DR4 alone $(p=0 \cdot 12)$. In several multiple case families disease susceptibility has been found to follow this haplotype. ${ }^{6}{ }^{19}$ In a previous study we have shown that HLA$\mathrm{A} 1, \mathrm{~B} 8, \mathrm{Cw} 7, \mathrm{DR} 3$ is strongly associated with intolerance to gold salts in patients with RA. ${ }^{20}$ Because of the increased frequency of this haplotype in RA it seems that patients with RA are unfortunately at high risk for gold salt intolerance. A similar finding may apply to toxic reactions to D-penicillamine therapy. ${ }^{20}$ Our data confirm previous reports that the frequency of the $\mathrm{A} 1, \mathrm{~B} 8, \mathrm{Cw} 7, \mathrm{DR} 3$ haplotype is the same in RA patients with and without Sjögren's syndrome, whereas this haplotype has an increased frequency in patients with primary Sjögren's syndrome. ${ }^{22} 23$ Other haplotype combinations involving DR3 have no significantly increased risk for RA. We have previously reported the association of HLA-DR2 with an increased risk for RA in a larger series of patients. ${ }^{7}$

Our results support the hypothesis that susceptibility to RA is controlled by a gene, or a group of genes, in the HLA region of chromosome 6 , and show that only certain haplotypes carrying HLADR4 or DR3 are at increased risk. The latter finding could be explained by linkage disequilibrium between the susceptibility gene(s) and the HLA loci. The variety of associations between HLA and RA in various ethnic groups reported in the literature also supports this hypothesis. Finally, the similarity between haplotypes associated with increased risk in our study, and those frequently described in multiple case families suggests that similar genetic mechanisms underlie familial and non-familial RA.

\section{References}

1 Stastny P. Mixed lymphocyte culture typing cells from patıents with rheumatoid arthritis. Tissue Antigens 1974; 4: 571-91.

2 McMichael A J, Sasazuki T, McDevitt H O, Payne R O. Increased frequency of HLA-Cw3 and HLA-Dw4 in rheumatoid arthritis. Arthritis Rheum 1977; 20: 1037-42.

3 Panayi G S, Wooley P H. B lymphocyte alloantigens in the study of the genetic basis of rheumatoid arthritis. Ann Rheum Dis 1977; 36: 365-8.
4 Thomsen M. Morling N, Snorrason E, Svejgaard A, Sorensen S F. HLA-Dw4 and rheumatoid arthritis. Tissue Antigens 1979; 13: $56-60$.

5 Kahn M A, Kushner I, Weitkamp L R, Genetics of HLAassociated disease; rheumatoid arthritis. Tissue Antigens 1983; 22: $182-5$.

6 Nunez G, Moore S E, Ball G V, Hurd E R, Stastny P. Study of HLA antigens in ten multiple-case rheumatoid arthritis families. J Rheumatol 1984; 11: 129-35.

7 Legrand L. Lathrop G M, Marcelli-Barge A, et al. HLA-DR genotype risks in seropositive rheumatoid arthritis. Am J Hum Genet 1984; 36: 690-9.

8 Nyulassy S, Ravingerova G, Zavarona E, Buc M. HLA antigens in rheumatoid arthritis. Lancet 1974; i: 450 .

9 Dryll A, Bardin T, Degegre N, et al. Polyarthrite rhumatoide et système HLA: une étude des haplotypes chez 81 patients. In: Proceedings of the 15th International Congress of Rheumatology, Rev Rhum Paris. 1981: resumé 10.

10 Karsh J, Klippel J H, Mann D L, et al. Histocompatibility antigen combinations in rheumatoid arthritis. Clin Exp Rheumatol 1983; 1: 11-5.

11 Raum D, Awdeh Z, Glass D, et al. Extended haplotypes of chromosome 6 in adult rheumatoid arthritis. Arthritis Rheum 1984; 27: 516-21.

12 Ropes M W, Bennett G A, Cobb S, Jacox R, Jessar R A. Revision of diagnostic criteria for rheumatoid arthritis. Bull Rheum Dis 1958; 9: 175-6.

13 Pellegrino M A, Ferrone S, Dierich M P, Resifel R A. Enhancement of sheep red blood cell human lymphocyte rosette formation by the sulfhydryl compound 2-aminoethylisothiouronium bromide. Clin Immunol Immunopathol 1975; 3: 324-33.

14 Alper C A, Boenisch T, Watson L. Genetic polymorphism in human glycine-rich beta-glycoprotein. J Exp Med 1972; 135: 68-80.

15 Bishop Y M, Fienberg S E, Holland P W. Discrete multivariate analysis: theory and practice. Cambridge, Mass: MIT Press, 1975.

16 Smouse P E. Statistical analysis of HLA-disease associations: In: Sing C F, Skolonick M, eds. Genetic analysis of common disease: applications to predictive factors in coronary disease. New York: Alan Liss, 1979: 545-51.

17 Kendall M, Stuart A. The advanced theory of statistics. Vol 2, 4th ed. London: Griffen, 1979.

18 Baur M P, Danilovs J A. Population analysis of HLAA,B,C,DR, and other genetic markers. In: Terasaki P I, ed. Histocompatibility testing 1980. Los Angeles: UCLA Tissue Typing Lab, 1980.

19 Hazelton R A, Dick H M, McKay S, Sturrock R D. Immunogenetic insights into rheumatoid arthritis: a family study. $Q J$ Med 1982; 203: 336-40.

20 Bardin T, Dryll A, Debeyre N, et al. HLA system and side effects of gold salts and D-penicillamine treatment of rheumatoid arthritis. Ann Rheum Dis 1982; 41: 599-601.

21 Wooley P H, Griffen B J, Panayi G S, Batchelor J R, Welsh $\mathrm{K} I$, Gibson T J. HLA-DR antigens and toxic reaction to sodium aurothiomalate and D-penicillamine in patients with rheumatoid arthritis. $N$ Engl $J$ Med 1980; 303: 300-2.

22 Moutsopoulos H M, Mann D L, Johnson A H, Chused T M. Genetic differences between primary and secondary sicca syndrome. $N$ Engl $J$ Med 1979; 301: 761-3.

23 Wilson R W, Provost T D, Bias W B, et al. Sjögren's syndrome: influence of multiple HLA-D region alloantigens on clinical and serological expression. Arthritis Rheum 1984; 27: 245-53. 